\title{
Análise epistemológica dos sistemas de informação gerenciais
}

\author{
Anderson Ravanello e Felipe Belão Iubel \\ ravanello@gmail.com, falamestre@gmail.com
}

\begin{abstract}
Resumo. Este trabalho analisa o conceito dos sistemas de informação gerenciais, amplamente utilizados nas organizações, do ponto de vista da docência da disciplina homônima e da experiência profissional e científica dos autores, contemplando o panorama histórico da sua concepção, as variáveis macro econômicas que estimularam seu crescimento e a literatura mais comumente usada na docência. Assim, são encontradas divergências entre as necessidades corporativas, o objetivo primário dos sistemas de informação e a forma através dos quais os mesmos são ensinados nas cadeiras da academia. Ao final, são propostas aproximações teóricas entre as necessidades organizacionais e a forma de estudo. Também são apresentadas sugestões para possíveis pesquisas na área, a fim de se esclarecer questionamentos que permanecem sobre os sistemas de informação e suas definições e origens epistemológicas.
\end{abstract}

\section{Introdução}

Sistemas de informação gerenciais são ferramentas automatizadas aplicadas pelas organizações para exercer controle, obter formalização e padronização, estimular a comunicação e a previsibilidade de comportamento e de ação dos membros das equipes organizacionais com o fim de aprimorar a eficiência das empresas. Estas ferramentas têm sido usadas nas organizações desde a popularização dos equipamentos computacionais nos ambientes profissionais, estimulados pela diminuição dos custos administrativos que a aplicação destas provém, pelo advento da intensificação das burocracias departamentais, da mecanização, da produção massiva e do aumento geral do conhecimento acumulado pela população.

Hoje, as ferramentas computacionais tornaram-se tão usuais que muitos aspectos dos indivíduos já se mesclam às estruturas sociais promovidas por estas ferramentas. $\mathrm{O}$ mesmo acontece com as organizações, uma vez que o uso de equipamentos computacionais torna-se tão usual que as empresas tornam-se, em muitos aspectos de sua eficiência e competitividade, dependentes dos computadores e dos sistemas baseados nestes.

Neste estudo serão realizados revisão bibliográfica, estudo epistemológico e análise histórica da disciplina de sistemas de informação e sua inserção no estudo de administração, usando as duas obras mais populares para o ensino da disciplina de Sistemas de Informações Gerenciais disponíveis em português, contemplando o panorama histórico das décadas de 1970 a 2000 e o estudo da evolução dos sistemas, das estruturas organizacionais e da literatura técnica nesta época. 


\section{Revisão bibliográfica - Sistemas de informação}

Sistemas de informação são perspectivas ou respostas organizacionais para desafios propostos pelo ambiente, construídos com base em equipamentos computacionais, pessoas e conhecimento, visando obter vantagem competitiva através da integração dos sistemas à estratégia organizacional, usando as ferramentas para auxiliar na gestão de inovação, busca de novos produtos e serviços, apoio à tomada de decisão e apoio operacional. Os sistemas tornam-se parte integrante das organizações através da inserção das regras e procedimentos prescritos da empresa em seu código operacional, passando então a afetar as organizações nos níveis econômicos, administrativos e comportamentais. O estudo dos sistemas de informações gerenciais divide-se no estudo dos seus componentes físicos - o hardware, seus componentes técnicos aplicados - o software e as ferramentas de telecomunicações utilizadas para o transporte das informações bem como a combinação destes três fatores para a construção de ferramentas complexas que contribuam para o incremento da eficiência das organizações.

No nível econômico, o efeito imediato na organização é a diminuição das equipes de trabalho no nível da gerência operacional, uma vez que os sistemas são capazes de incluir regras, padrões e controles de produtividade que suplantam a necessidade de capatazia das organizações focadas em eficiência. Adicionalmente, equipes profissionalizadas passam a ser mais eficientes em suas tarefas, uma vez que a velocidade dos fluxos de informação influencia a velocidade de tomada de decisão, permitindo um maior dinamismo às organizações. As características técnicas dos sistemas computacionais também permitem transcender fronteiras de tempo e espaço, permitindo a execução de tarefas, prestação de serviços e efetivo exercício das atividades que agregam valor ao core business da empresa sem distinção de hora ou local, o que, por sua vez, permite a integração de equipes remotas de trabalho, diminuindo custos e aumentando lucros.

Os impactos comportamentais que são gerados pela implantação de sistemas de informação iniciam-se na formalização das tarefas, o que pode efetivamente obrigar os trabalhadores a seguirem padrões anteriormente frouxamente aceitos, ou ainda ao oferecer a não refutabilidade das ações em ambiente laboral. Outras formas de impactos comportamentais que são encontrados após a implantação de sistemas referem-se à impessoalidade das ações computacionais, uma vez que não se espera identificação social dos trabalhadores com as ferramentas automatizadas, uma vez que é impossível para o projeto de sistemas incluir as regras não formalmente prescritas da organização.

Finalmente, percebe-se que sistemas de informação apresentam uma nova dimensão da organização, dada sua complexidade sócio-técnica e sua influência em todo o escopo organizacional. Esta dimensão abrange desde a percepção dos desafios empresariais do ambiente, o planejamento estratégico e coordenação do trabalho, até o controle das mudanças - conceito este estudado através da análise das organizações burocráticas que diz que a eficiência máxima é obtida quando a menor quantidade possível de recursos é aplicada para vencer um desafio, sendo que isto só pode ser atingido quando as regras para a solução do desafio ou o desafio per se são estáveis ou pouco mutáveis [Laudon et al, 2004], [Mota et al, 2004], [O’Brian, 2002].

As competências do gerente organizacional responsável pelos sistemas de informações gerenciais iniciam-se em sua capacidade de determinar qual o papel que 
deve ser desempenhado pelos sistemas de informação nas empresas, conhecimento dos seus elementos técnicos e lógicos, os impactos de sua aplicação nas organizações, a influência da Internet nos negócios e quais os desafios gerenciais para a construção de sistemas de informações eficientes. Para se determinar o papel dos sistemas na organização, há necessidade de se compreender os diversos tipos de sistemas de informações que podem ser aplicados nas organizações desde sua atuação como suporte à variadas funções negociais, o que gera a necessidade de integração aos processos negociais, até o amplo espectro de impactos e benefícios gerados na organização, sendo que os impactos muitas vezes são inevitáveis e os benefícios, nem sempre garantidos.

As organizações reagem de maneira diferente às diferentes implementações de sistemas informacionais. É importante que se conheça os impactos que sistemas de informação geram nas organizações, qual o grau de suporte que os sistemas de informações podem dar às tarefas de gerência, como usar sistemas de informação para obter vantagem estratégica nas organizações,e por que é difícil de se construir sistemas de informações de sucesso, incluindo sistemas que promovem vantagens competitivas através de mudanças. Ser capaz de interagir com todas estas variáveis é uma aptidão necessária dos gestores.

A aplicação de tecnologia nos processos de negócio altera a percepção de valor e os modelos negociais utilizados previamente nas organizações. $\mathrm{O}$ advento do comércio eletrônico altera as relações entre a organização e seus fornecedores, clientes, colaboradores e concorrentes. A convergência de informações, possibilitada pela Internet, permite maiores facilidades de coordenação de processos negociais, aumento de velocidade de colaboração e integração entre os colaboradores de maneiras inéditas. As inovações propostas pelas novas vias negociais trazem novas oportunidades, como um mercado global repleto de possibilidades de negócios como também novos desafios, como exposição de processos críticos do negócio em ambiente de acesso público e irrestrito.

Como já foi visto, existem impactos sociais e econômicos que surgem da implantação de sistemas informacionais. Os aspectos sociais levantam questões éticas que precisam ser consideradas no projeto de sistemas eficientes. Alguns destes aspectos são a inclusão da sociedade digitalmente excluída, a separação do tempo de dedicação ao trabalho e ao lazer e os aspectos de saúde física e mental que são afetados pelo uso continuo de computadores.

Parte do estudo de sistemas de informação é o conhecimento dos recursos tecnológicos computacionais - o hardware e o software - aplicado nas soluções de sistemas. É importante buscar, de fontes externas, as tendências de equipamentos e programas, suas capacidades e custos, e sua aplicabilidade no ambiente empresarial, levando em conta que a organização deve aplicar as ferramentas corretas em busca de maior eficiência - ou seja, não aplicar nem mais nem menos tecnologia ou investimentos do que o necessário.

Além das aplicações técnicas da tecnologia, existe ainda a necessidade de se gerenciar corretamente os dados da organização. Esta gerência de dados é feita utilizando-se ferramentas computacionais específicas chamadas de bancos de dados e suas aplicações técnicas modernas, como data mining, e data marts. A gerência dos dados só será efetiva quando forem conhecidas todas as necessidades de negociais de informações dos níveis estratégicos e operacionais da organização.

A correta aplicação das ferramentas de telecomunicações existentes é uma vantagem estratégica na organização que precisa contingenciar todas as variáveis 
apresentadas até este ponto. Existem cada vez mais diversas tecnologias, tipos de serviço, disponibilidades e custos que precisam ser analisados para a efetiva implantação de uma estrutura de telecomunicações que seja capaz de sustentar as necessidades das organizações. Esta sustentação das necessidades organizacionais deve levar em conta as expectativas dos clientes, os processos centrais de negócio e as disponibilidades de recursos.

O advento da Internet barateou muito dos custos de telecomunicações, permitindo que muitas empresas pudessem posicionar perante um mercado numeroso, porém sem face. Baixos custos, popularização de tecnologia e amplo acesso expandem a cada dia o mercado de comércio pela Internet, porém, não sem riscos; a Internet continua sendo um local praticamente sem lei e o comércio através dela, apesar de ser a forma de negócios que mais espera-se crescer no futuro próximo [Laudon et al, 2004], ainda apresenta desafios culturais tanto aos vendedores quanto aos compradores. De um lado, posicionam-se os vendedores que apesar de precisarem suplantar os desafios da logística global têm menos custos fixos que comerciantes de balcão, e de outro, os compradores, que com amplo acesso da informação, passam a ter maior poder de conhecimento do produto, apesar de terem que confiar nas informações que encontram na Internet.

A gerência de dados efetiva da organização leva ao nível de gestão do conhecimento organizacional. Os sistemas de informações servem como base para o processo de criação, distribuição e compartilhamento do conhecimento. Esta capacidade se dá através dos recursos que interligam, controlam, organizam e focam a geração do conhecimento nos objetivos organizacionais.

O processo de tomada de decisão nas organizações pode ser auxiliado por sistemas de suporte à decisão, que são um ramo especializado dos sistemas de informações gerenciais. Este auxílio à tomada de decisões é oferecido na forma de segregação e demonstração, de maneira simplificada, das informações que foram previamente declaradas como informações estratégicas. Um desafio apresentado por este recurso dos sistemas informacionais reside em determinar corretamente qual informação pode ser declarada como estratégica e, principalmente, qual informação mantém-se estratégica a despeito das mudanças ambientais que ocorrem na organização e quais devem compor cada um dos cenários decisórios desejados pela alta direção.

Por vezes o processo decisório auxiliado por sistemas de informações não apresenta a eficiência desejada ou ainda descobre-se, ao arregimentar os dados necessários, que não se dispõe dos mesmos em quantidade ou qualidade necessária. Quando esta ocorrência torna-se realidade, os sistemas de informação podem ser usados para estimular a mudança na organização, através da rápida re-adequação das necessidades e disponibilidades de informação, da adesão de novos planos negociais e da expansão da automatização da informação. Este tipo de mudança, no entanto, carrega uma das maiores dificuldades das estruturas burocráticas, que é o próprio conceito de mudança; apesar das ferramentas computacionais aceitarem com impessoalidade quaisquer novas funções, os operadores humanos não são do mesmo modo programáveis, e negligenciar a dimensão humana dos sistemas de informações gerenciais é um estímulo muito forte para o seu fracasso.

Quando se completa um ciclo de mudanças com sucesso, no entanto, muda-se não apenas a ferramenta sócio-técnica denominada sistema de informação. Modifica-se também o valor que a informação agrega sobre os produtos e serviços da empresa, as maneiras como a empresa passa a medir seu valor e custo de produto e serviço e como é 
possível então utilizar os sistemas de informação para gerar mais eficiência - seja sob a forma de lucro ou sob a forma de diminuição de custos ou ainda de acréscimo de dinâmica no processo de produto. Esta mudança de valores que trás atenção para o efeito do processo informacional naquilo que é o interesse do cliente, pode determinar novas estruturas de poder dentro da organização, uma mudança que pode ser não desejada pelas estruturas correntes de poder, sendo que a iminência da ocorrência desta mudança depende de recursos e da anuência das estruturas atuais, o que, em caso de ocorrência de divergências de interesse entre as pessoas e as instituições, pode culminar em falha de implantação do sistema.

Considerando-se que seja possível tangi-versar todas as variáveis e vencer todos os desafios apresentados pela implantação de sistemas de informação, cabe a preocupação de mantê-los funcionando, tanto pelo gerenciamento de segurança, efetuado pelo exercício de auditorias de segurança que buscam garantir que as pessoas certas acessem as informações que precisam quanto pela gestão de qualidade de informações e treinamento dos usuários.

Um aspecto final dos sistemas de informações é que estes são capazes de agir, dada uma infra-estrutura eficiente de telecomunicações, além das fronteiras das nações, permitindo, além dos negócios internacionais, a gerência de unidades ou companhias inteiras à distancia. Isso traz vantagens negociais importantes, porém propõem novos desafios, principalmente os que se referem às culturas, às legislações e às formas de comunicação variadas encontradas no ambiente organizacional internacional. Para compreender tal fato é importante analisar o panorama histórico no qual os sistemas de informação estão inseridos e no qual foram criados. Para isso, segue a contextualização econômica do mesmo.

\section{Panorama Histórico - Tecnologia e Economia}

A economia mundial sofreu grandes alterações a partir da década de 60 que determinaram uma distinção ainda maior entre as nações ricas e desenvolvidas e as nações pobres e subdesenvolvidas. Isso se consolidou na década de 70 , na qual diversas crises internacionais terminaram por estabelecer um declínio da economia mundial, dentre tais crises pode-se destacar a crise do petróleo. Esta crise foi o primeiro de uma sequiência de eventos que acabaram catalisando o ritmo da economia de hoje (ROSSETTI, 2002).

A primeira crise do petróleo ocorreu em 1973 e foi uma espécie de represália dos países árabes produtores de petróleo e membros da OPEP ao apoio dos Estados Unidos e da parte ocidental da Europa ao Estado Israelense durante a guerra do Yom Kipur. Esse embargo ocasionou, principalmente, um aumento significativo do preço do barril de petróleo no mercado internacional, recessão e desestabilização da economia mundial. Esta desestabilização foi caracterizada por um aumento, em questão de alguns dias, do preço do barril de petróleo cru da ordem de 35\% (ROSSETTI, 2002).

O segundo momento de crise do petróleo também ocorreu ainda durante a década de 70, mais especificamente em 1979, e foi provocado pela revolução que estabeleceu a república islâmica no Irã. É importante notar que este país era o segundo maior exportador de petróleo na época e a crise determinou um preço recorde para o barril no início da década de 80 . Isto agravou a situação econômica dos paises que ainda não haviam se recuperado do primeiro momento da crise (ROSSETTI, 2002). 
Portanto, o início da década de 80 foi marcado por elevado desemprego e grande pressão inflacionária. Além disso, essa década foi marcada pela chamada crise da dívida, durante a qual até mesmo os países desenvolvidos encontravam dificuldades em saldar seus compromissos financeiros. Foi um período com grande número de falências de empresas nos Estados Unidos e Europa (MANKIW, 1999).

A década de 90 é marcada por um cenário não muito melhor que o da década anterior. Em 1995, a Crise do México abalou o cenário internacional e comprometeu a confiança no livre comércio. Em 1997, a Crise dos Tigres Asiáticos comprometeu a economia mundial, prejudicando as atividades de importação e exportação de muitos países, inclusive do Brasil. Em 1998, a Crise da Rússia agravou ainda mais a situação, aumentando as taxas de desemprego (HELD \& MCGREW, 2001).

É neste cenário econômico que o século XXI desponta trazendo consigo a economia da informação, onde tem-se um inédito recurso inexaurível - a informação. Apesar dos meios ainda serem saturáveis, apesar do público alvo ser finito, a informação é um recurso que, em seu estado bruto, não se acaba. Considerando-se esta propriedade da informação, pode-se considerar que, uma vez que o minério de conhecimento é altamente disponível, o que tornam-se escassos são os meios de manipulá-lo ou ainda os indivíduos com capacidade de fazê-lo.

O crescimento da economia no pós-guerra imperou em dois eventos que estimularam a produção de conhecimento técnico cientifico na área da informática: de um lado, os profissionais americanos egressos dos projetos militares encontravam melhores oportunidades de trabalho no mercado privado, e do outro, a IBM conseguia contratos mais rentáveis com desenvolvimento de software para empresas, mais notadamente nas áreas de planejamento de manufatura, do que no setor público, que fora até então seu mais lucrativo setor. As empresas nesta época adentravam em um paradigma organizacional de burocracia departamental, iniciando-se as necessidades de controle e formalização da informação da mesma maneira que era necessário controlar as entradas e saídas de produtos, funcionários e insumos. A convergência do aumento da força de trabalho tecnicamente capacitada disponível, a pujança econômica e os avanços científicos e tecnológicos da época, permite o nascimento dos primeiros sistemas informatizados de controles de entrada e saída de material, que depois seriam chamados de MRP - manufacturing resource planners (ROSSETTI, 2002).

Estes sistemas permitiram a extração de informações, exercício de controle e inferências técnicas sem precedentes. Através do pragmatismo cultural conhecido do povo americano, iniciou-se o esforço de aplicar esta mesma ferramenta técnicacientífica em todas as áreas da organização, em busca de estimular ainda mais a eficiência da máquina organizacional. A competição interna nas organizações permitiu que a tendência da informatização fosse considerada como estratégica pelos gestores.

Os sistemas cresceram então em complexidade e popularidade. De controles de estoque, se expandiram para suas áreas co-irmãs, contabilidade e compras, evoluindo então para todas as áreas da organização, chegando recentemente até o balcão de vendas e, graças ao advento das redes convergentes ilustrado pelo impacto da Internet, em muitos casos já suplanta a própria necessidade de um ponto de venda físico através de sua disposição na rede mundial de computadores. Os sistemas de informações gerenciais, complexos e abrangentes, passaram a ser estudados, enquanto disciplina formal da educação em administração, no Brasil, em meados da década 90, fruto em grande parte da quebra de monopólio e conseqüente popularização do microcomputador tanto nas empresas quanto nos lares brasileiros (ROSSETTI, 2002). 
A Internet passou a ser uma realidade para o país em torno de 1994, através da instalação, em São Paulo, da FAPESP. Cerca de meia década após, chegam até o corpo discente, as primeiras publicações envolvendo seus impactos sobre os negócios e as organizações. O ritmo proposto pela economia da organização passa a ser o ritmo natural dos negócios no fim desta década, influenciando não apenas os negócios mas também as vidas dos indivíduos.

Dentro desse contexto econômico, posteriormente pretende-se apresentar uma análise epistemológica, do ponto de vista teórico e também dedutivo, dos sistemas de gestão da informação. A intenção é demonstrar a evolução dos conceitos e apresentar uma crítica conceitual ao modelo estabelecido em relação ao que, de fato, era e continua sendo praticado na área.

\section{Evolução Teórica - Análise Epistemológica}

A revisão de literatura apresentada e a evolução dos sistemas de gestão de informações demonstram a presença do racionalismo cartesiano na construção do conhecimento da área. Sendo assim, no desenvolvimento dos sistemas, a dúvida é tratada como instrumento de combate à própria dúvida, com uma clara disposição de todas as questões a uma investigação científica, com encadeamento de razões. As questões são tratadas de maneira unitária e da forma mais cristalina possível, buscando um aprimoramento a partir da experiência. A exatidão e a forma de dividir as questões em parcelas para o estudo corroboram com a afirmação racionalista e cartesiana desenvolvida pelo filósofo francês René Descartes (1973) em seu livro Discurso sobre o Método, que data de 1637.

As informações recebidas são tratadas de maneira escrupulosa e sua justificação científica sempre é buscada. A procedência é verificada dividindo-se o assunto em quantas partes possível e necessário, com ordenamento do mais simples para o mais complexo. A coerência geral, finalmente é obtida por meio da enumeração e revisão cuidadosa das conclusões, sem omissões ou erros.

Ainda que exista essa inspiração no método de Descartes (1973) que, por sua vez, foi influenciado pela geometria, principalmente no que diz respeito ao encadeamento das razões e enumerações, o conhecimento dos sistemas de informação gerenciais não deixa de considerar as pessoas. É importante notar também, que o desenvolvimento teórico dos sistemas de informação ocorreu em grande parte nos Estados Unidos, influenciado pelo pragmatismo histórico da antropologia americana. Assim, a aplicação das ciências exatas da engenharia, da matemática e da própria estatística conduzia a projetos de sistemas baseados na previsibilidade, replicabilidade e relação de causa e efeito.

Contudo, quem utilizava tais sistemas eram pessoas e essas pessoas exigiam, cada vez mais, uma adaptação dos sistemas às suas necessidades e suas características individuais. Dessa forma, o ponto de vista unitário passou a ser utilizado na abordagem teórica do assunto, mas a busca da adequação à individualidade foi o que predominou na prática e na construção do próprio conhecimento. $\mathrm{O}$ impacto da formalização e a maneira de lidar com tal impacto levaram a uma consciência cada vez maior das pessoas envolvidas com os sistemas de informação. 
Esse é um dos sintomas que, em parte, descaracterizava a predominância do racionalismo cartesiano na produção do conhecimento. Portanto, as características sociológicas e psicológicas relacionadas às pessoas também passaram a ser importantes.

Sendo assim, engenheiros contratados desenvolviam sistemas corporativos para grandes empresas na época em que o conhecimento dos sistemas de informação se construía efetivamente. A ciência exata predominava. O método cartesiano apresentavase como fundamental. No entanto, a visão matemática e cartesiana que tais engenheiros aplicavam na formulação era, posteriormente, readequada às reais necessidades dos indivíduos.

Com base nisso, pode-se observar que a análise da literatura é tipicamente cartesiana e divide o problema em diversas partes, analisando-as do mais simples para o mais complexo. Considera-se primeiramente o instrumento que possibilita o desenvolvimento desses sistemas de informação, ou seja, a ferramenta computacional.

A resposta matemática e unitária é readequada ao ponto de vista dos indivíduos, as suas variáveis comportamentais e as suas necessidades pessoais. A padronização de comportamentos e a formalização de processos passam a levar em conta tais fatores. Assim a eficiência e o apoio à tomada de decisão somente concretiza-se mediante a consideração das necessidades dos usuários do sistema, pois a compreensão dos objetivos da organização por parte destes é fundamental.

O gerenciamento da antagonia dos atores dentro das organizações é fundamental para se obter o respaldo em busca da satisfação dos interesses e das diferenças pessoais dentro da empresa. Muitas vezes a negociação mostra-se como alternativa para a consolidação dessa gerência sobre as diferenças de opiniões, em oposição ao modelo puramente cartesiano. Apenas dessa maneira os sistemas de informação gerenciais efetivam-se e a sinergia obtém-se.

Conquanto, as pessoas inseridas na organização não podem ser as únicas consideradas. $\mathrm{O}$ atendimento às expectativas individuais dos clientes, conforme observado na revisão de literatura, também se apresenta como um dos fatores condicionantes do sucesso na busca pela padronização e pela rotinização dos processos e pelas conseqüentes eficiência e eficácia dos resultados. $\mathrm{O}$ funcionamento adequado do modelo de sistemas de informação gerenciais se torna menos cartesiano para atentar aos problemas das pessoas.

No decorrer da literatura, há citações do treinamento, da profissionalização e dos antecedentes de cada indivíduo, e de como estes fatores influenciam nos resultados dos sistemas de informação. Esta influência é exercida de maneiras diversas, podendo ser exemplificada, entre outras maneias, como a capacidade de cada indivíduo participante do sistema organizacional em compreender, interpretar e aderir às regras e procedimentos formalizados pela implantação de sistemas de informação, como também a compreensão que, novamente, cada indivíduo possui acerca dos objetivos organizacionais. Por vezes, a publicação de uma regra não a torna imediatamente internalizada, ou seja, em geral não ocorrerá, entre os seres humanos, o mesmo comportamento da máquina de adesão automática a novas regras ou procedimentos.

Finalmente, ainda existe a cultura organizacional que carrega signos e ritos que não podem ser automatizados ou transportados para os sistemas de informação. Considerando-se que a cultura pode ser uma variável importante da organização, o cartesianismo dos sistemas de informações, e, por consequiência, o seu estudo, peca ao não ser capaz de informatizar ou automatizar também este aspecto da organização, que, 
em sua forma bruta, é composto de informações e suas interpretações pelos indivíduos participantes da organização.

\section{Conclusão}

Através da análise da bibliografia que abrange o estudo de sistemas de informações gerenciais, observou-se que estes objetivam aumentar a eficiência das organizações através da automatização dos fluxos informacionais e que esses fluxos permeiam todo o ambiente em que se encontra o exercício de esforços da organização, desde os clientes, os fornecedores, os interessados externos e os membros da organização. A bibliografia analisada propõe a fragmentação dos problemas informacionais da organização entre o entendimento das necessidades de informação na cadeia produtiva, o conhecimento técnico necessário para sua satisfação e a aplicação das ferramentas corretas e suficientemente eficientes para relação entre as necessidades da organização e as ferramentas da organização.

Existem, no entanto, áreas da organização que são atingidas pelos sistemas de informações gerenciais, que influenciam sua eficiência, mas que não podem ser apresentadas de maneira matematicamente científica. Estas áreas organizacionais são apresentadas pelo aspecto humano das mesmas e esses determinam a necessidade por análises mais completas.

Assim, o modelo cartesiano, que é claramente utilizado na literatura, é complementado por essa visão mais ampla e que considera as pessoas como principais usuárias dos sistemas de informações gerenciais. As reais necessidades dos indivíduos passam a integrar assim um dado importante para a construção e utilização dos sistemas e modelos.

Por conseqüência, a eficiência, eficácia e o lucro buscados com a implementação dos sistemas são atingidos apenas quando as características das pessoas, como seu arcabouço cultural, bem como as características organizacionais, como a cultura interna, são respeitados e considerados. Isso, aliado ao aspecto matemático-lógico apresentado pela literatura, estabeleceu e continua promovendo a evolução dos sistemas.

No entanto, os autores, por apresentar uma visão que, ainda que teórica, é muito influenciada por experiências pessoais, acreditam que muito precisa ser feito e estudado com relação a esse tema. Tal limitação da presente pesquisa, serve de estímulo para futuros estudos que possam aprofundar o conhecimento na área e proporcionar elucidações para as perguntas que permanecem sem resposta. 


\section{Referências}

DESCARTES, René. (1973) Discurso do método: Meditações ; Objeções e respostas ; As paixões da Alma ; Cartas. São Paulo: Abril Cultural.

HELD, David; MCGREW, Anthony. Prós e contras da globalização. Rio de Janeiro: Zahar, 2001.

LAUDON, Kenneth; LAUDON, Joan. (2004) Management Information Systems: Business and the Internet. MA: Prentice Hall.

MANKIW, N. Gregory. Introdução à economia: princípios de micro e macroeconomia. Rio de Janeiro: Campus, 1999.

MOTA, Fernando C. P., BRESSER-PEREIRA, Luiz C. (2003) Introdução à Organização Burocrática. São Paulo: Thomson Learning.

O’BRIAN, James P. (2003) Management Information Systems: Managing Information Technology in the E-Business Enterprise. Texas: Mcgraw-Hill.

ROSSETTI, José P. Introdução à economia. São Paulo: Atlas, 2002. 922 p. 